\title{
Penerapan Inovasi Resource Sharing dalam Mengurangi Tingginya Pengangguran di Provinsi Banten
}

\author{
Bambang Dwi Suseno ${ }^{1}$, Furtasan Ali Yusuf ${ }^{2}$, Syamsul Hidayat $^{3}$, Dewi Surani ${ }^{4}$ \\ ${ }^{1,2,3,4}$ Universitas Bina Bangsa, Banten, Indonesia
}

\begin{abstract}
The unemployment rate in the August 2019 period in Banten Province was the highest in Indonesia. The ability of Banten Province in preparing employment opportunities is at the lowest level compared to other provinces with the fact that the unemployment rate is $8.11 \%$. This research offers a breakthrough in the form of resource sharing innovation between manufacturing companies and training institutions in the form of models. The research location was conducted in the three largest industrial areas in Banten Province; Serang Regency, Cilegon City and Tangerang Regency. These areas have the highest number of unemployed among other areas in Banten. The data collection method used purposive sampling technique. Where the sample is selected from the apprenticeship population. The questionnaire in this study was distributed to all employees who took 3 in 1 program who had graduated and worked. There were 250 questionnaires distributed to all employees, and 217 employees filled out the questionnaire and it was managed appropriately. Data and hypothesis testing were carried out through the Structural Equation Modeling (SEM) method using the IBM AMOS version 22 application program. The results of this study found that the Skill Development Fund has a significant positive effect on Workforce Competence, the Skill Development Fund has a significant positive effect on the Skill Development Center, the Workforce Competence has a significant positive effect on the Skill Development Center, Workforce Competence has a significant positive effect on Resource Sharing Innovation, Resource Sharing Innovation Has a significant positive effect on Skill Development Center, Skill development center has a significant positive effect on Human Resource Industries Competitiveness, Resource Sharing Innovation has a significant positive effect on Human Resource Industries Competitiveness.
\end{abstract}

Keywords: skill development fund; workforce competence; skill development center; resources sharing innovation; human resources industries competitiveness

\begin{abstract}
Abstrak
Angka pengangguran di Provinsi Banten pada periode Agustus 2019 paling tinggi seIndonesia. Kemampuan Provinsi Banten dalam menyiapkan lapangan pekerjaan diurutan buncit dibandingkan provinsi lain dengan fakta tingkat pengangguran sebesar $8,11 \%$. Penelitian ini menawarkan terobosan berupa inovasi resource sharing antara perusahaan manufaktur dengan lembaga diklat berupa model. Lokasi penelitian dilakukan di tiga wilayah indsutri terbesar di Provinsi Banten yaitu Kab. Serang, Kota Cilegon dan Kab. Tangerang. Daerah tersebut memiliki jumlah penganggur yang paling banyak diantara daerah lainnya di Banten. Metode pengambilan data menggunakan teknik purposive sampling. Dimana sampel dipilih dari populasi pemagangan. Kuisioner dalam penelitian ini didistribusikan kepada semua karyawan yang mengikuti 3 in 1 yang sudah lulus dan bekerja. Ada 250
\end{abstract}

${ }^{3}$ Penulis Koresponden. mastersyah@gmail.com 
kuesioner yang dibagikan kepada semua karyawan, dan 217 karyawan mengisi kuesioner dan dapat dikelola dengan tepat. Data dan pengujian hipotesis dilakukan melalui metode Structural Equation Modelling (SEM) menggunakan program aplikasi IBM AMOS versi 22. Hasil penelitian ini menemukan bahwa Skill Development Fund berpengaruh positif signifikan terhadap Workforce Competence, Skill Development Fund berpengaruh positif signifikan terhadap Skill Development Center, Workforce Competence signifikan berpengaruh positif signifikan terhadap Skill Development Center, Workforce Competence berpengaruh positif signifikan terhadap Resource Sharing Innovation, Resource Sharing Innovation berpengaruh positif signifikan terhadap Skill Development Center, Skill development center berpengaruh positif signifikan terhadap Human Resource Industries Competitiveness, Resource Sharing Innovation berpengaruh positif signifikan terhadap Human Resource Industries Competitiveness.

Kata kunci: skill development fund; workforce competence; skill development center; resources sharing innovation; human resources industries competitiveness.

\section{PENDAHULUAN}

Data BPS menyebutkan, jumlah penduduk bekerja di Provinsi Banten meningkat dari tahun 2018 sebanyak 5,62 juta orang menjadi 5,68 juta orang pada 2019 ini. Dengan struktur lapangan pekerjaan utama terbesar meliputi perdagangan sebesar 23,88 persen atau 1.36 juta orang, industri pengolahan sebesar 19,97 persen atau 1.13 juta orang, pertanian, pertambangan dan penggalian sebesar 12,72 persen atau 722.120 orang (BPS, 2019).

Tabel 1. Jumlah Pengangguran Menurut Kab/Kota di Banten

\begin{tabular}{lcccc}
\hline \multirow{2}{*}{ Kabupaten/Kota } & \multicolumn{2}{c}{$\begin{array}{c}\text { Pengangguran } \\
\mathbf{( 0 0 0 )}\end{array}$} & \multicolumn{2}{c}{$\begin{array}{c}\text { Tingkat Pengangguran } \\
\text { Terbuka (TPT) }\end{array}$} \\
\cline { 2 - 5 } & $\begin{array}{c}\text { Agustus } \\
\mathbf{2 0 1 8}\end{array}$ & $\begin{array}{c}\text { Agustus } \\
\mathbf{2 0 1 9}\end{array}$ & $\begin{array}{c}\text { Agustus } \\
\mathbf{2 0 1 8}\end{array}$ & Agustus 2019 \\
\hline Pandeglang & 44 & 45 & 8,33 & 8,71 \\
\hline Lebak & 47 & 47 & 7,69 & 8,05 \\
\hline Tangerang & 164 & 164 & 9,70 & 8,91 \\
\hline Serang & 84 & 73 & 12,77 & 10,65 \\
\hline Kota Tangerang & 78 & 79 & 7,40 & 7,13 \\
\hline Kota Cilegon & 19 & 19 & 9,33 & 9,68 \\
\hline Kota Serang & 24 & 25 & 8,16 & 8,08 \\
\hline Kota Tangerang Selatan & 37 & 39 & 4,67 & 4,79 \\
\hline Jumlah & $\mathbf{4 9 7}$ & $\mathbf{4 9 1}$ & $\mathbf{8 , 5 2}$ & $\mathbf{8 , 1 1}$ \\
\hline \multicolumn{1}{c}{ Sum } & & & & \\
\hline
\end{tabular}

Sumber: BPS, (2019)

Berdasarkan tabel 1 terdapat dua wilayah industri yakni Kabupaten Serang, Kota Cilegon dan Kabupaten Tangerang sebagai basis perusahaan manufaktur ternayata paradoksial sebagai penyumbang tertinggi angka pengangguran di Provinsi Banten. Kabupaten Serang menjadi penyumbang tertinggi dengan angka 10,65\% disusul tertinggi kedua yaitu Kota Cilegon dengan angka 9,68\% dan Kabupaten Tangerang 8,91 \% (BPS, 2019). Padahal kalau kita cermati kabupaten/kota yang jumlah penganggurannya tinggi tersebut semisal Kabupaten Serang jumlah perusahaan besar sebanyak 847 unit, Kabupaten Tangerang 3.858 unit, dan Kota Cilegon 878 unit perusahaan (Suseno, 2019). Ironisnya angka pengangguran terbanyak justru didominasi oleh penganggur yang terdidik. Data terakhir menunjukkan bahwa jumlah penganggur terdidik yang telah menamatkan pendidikan Menengah Kejuruan (SMK) sampai dengan Februari 2019 
telah mencapai $13.03 \%$ adalah penyumbang tingkat pengangguran terbuka tertinggi diantara lulusan tingkat pendidikan lainnya (BPS, 2019).

Pengangguran di daerah industri menarik untuk dikaji karena daerah industri selayaknya dapat menyerap tenaga kerja sebanyak-banyak bagi masyarakat yang berada pada wilayah tersebut. Kenyataannya justru di daerah industri tersebut paling banyak jumlah penganggurannya. Padahal menurut Mulyadi, (2012) kawasan industri dapat memacu pertumbuhan ekonomi yang lebih tinggi, meningkatkan efisiensi dan kemudahan penyediaan infrastruktur, dan menyediakan lapangan kerja yang luas. Perkembangan daerah industri ternyata belum sepenuhnya dapat mengatasi permasalahan di kabupaten/kota di Provinsi Banten. Permasalahan tersebut antara lain kondisi sosial masyarakat sekitar, pertumbuhan ekonomi yang relatif rendah, pengangguran yang masih tinggi dan kemiskinan yang relatif masih tinggi.

Wicksell berargumentasi sebagaimana dikutip oleh Jonung (1989) dan Mouhammed (2011) bahwa pengangguran siklis disebabkan oleh investasi modal yang salah. Modal diinvestasikan pada daerah dimana tingkat pengembalian rendah.Temuan Mouhammed (2011) menyimpulkan bahwa ketersediaan pekerjaan adalah ukuran terbaik untuk melawan pengangguran siklus. Kondisi sama persis dengan apa yang tengah terjadi di Banten, dan itulah mengapa beberapa perusahaan memindahkan pabriknya ke luar Banten. Tingkat pengembalian rendah ini pula menjadi permasalahan sosial lainnya di masyarakt Banten.

Disamping itu terdapat temuan yang menarik tentang kebijakan pembangunan melalui peningkatan investasi berdampak pada peningkatan pendapatan walaupun terdapat ekses berupa tingkat ketimpangan yang semakin lebar (Winardi, 2017). Jika pengangguran berlangsung dalam jangka panjang akan menyebabkan mental yang kurang baik di masyarakat, sebagaimana temuan dari (Machin \& Manning,1999)

Berdasarkan deskripsi diatas nampaknya terdapat kondisi paradox dimana daerah dengan jumlah perusahaan manufaktur melimpah, namun memiliki angka pengangguran tinggi, sehingga menarik dan penting untuk diteliti agar ditemukan jawaban untuk memberikan rekomendasi bauran kebijakan secara inovatif dan berkelanjutan bagi pemerintah Provinsi Banten, Kabupaten/Kota di wilayah ini.

Model ekonomi berbagi (sharing economy) menjadi keniscayaan dalam perekonomian global yang mengharuskan efisiensi dan kecepatan beradaptasi memenuhi dinamika kebutuhan pelanggan. Adaptasi dari ekonomi berbagi inilah yang kemudian dikembangkan dalam menurunkan angka pengangguran di Provinsi Banten. Pemerintah daerah tidak akan sanggup menyediakan anggaran yang cukup dan dalam menyiapkan teknologi, peralatan, bahan praktek serta instruktur untuk memberikan tambahan komptensi bagi para pencari kerja. Para pencari kerja di Provinsi Banten mayoritas masih menghadapi gap yang lebar antara kompetensi yang disyaratkan dunia industri dengan apa yang diperoleh dari lembaga pendidikan maupun dari lembaga pelatihan (diklat). Hal ini secara laten akan selalu tertinggal mengingat lembaga diklat akan selalu tertinggal dalam menyiapkan berbagai sumberdaya pendukung baik peralatan praktek yang memenuhi standar teknologi, peralatan dan bahan praktek terkini sebagaimna yang tengah diterapkan dalam dunia industri.

Teori klasik tentang tenaga kerja dari Pigou, (1933) berpendapat bahwa pasar tenaga kerja terdiri dari permintaan dan penawaran tenaga kerja. Permintaan tenaga kerja adalah permintaan turunan, yang diperoleh dari bagian yang menurun dari produk marginal tenaga kerja. Kemudian Mouhammed, (2011) memberikan sebuah kesimpulan dari teori Pigou, (1933) bahwa banyaknya pekerjaan tidak berarti bahwa tidak ada pengangguran. Sedangkan pengangguran itu sendiri menurut Hadroj, (2016) seseorang dianggap menganggur jika tidak memiliki pekerjaan dan siap untuk bekerja. Yang sibuk (dipekerjakan) dianggap sebagai orang yang memiliki pekerjaan yang dibayar, bahkan ketika absen bekerja karena alasan sakit, berlibur atau mogok.

Teori Keynesian (Rodriguez, 2015) berlainan pendapat dengan teori klasik tentang pengangguran bahkan menolak kesimpulan klasik tentang lapangan kerja penuh dalam ekonomi 
kapitalis. Depresi di seluruh dunia pada tahun 1930-an melahirkan ekonomi Keynesian (Dutta, n.d.). Teori Pengangguran Klasik tidak ada hubungannya dengan pandangan klasik tentang pekerjaan yang muncul oleh para ekonom paling relevan di abad ke-18 seperti Adam Smith atau David Ricardo (Rodriguez, 2015).

Beberapa penelitian-penelitian terdahulu tentang pengangguran yang telah dilakukan oleh (Yacoub, 2012; Setiyawati and Hamzah, 2007; Heriansyah, Nuraini and Kusuma, 2018; Santoso, 2014; Imsar, 2018; Budiani, 2005; Baeti, 2013; Alghofari, 2010; Hadroj, 2016; Machin and Manning, 1999; Winardi, 2017). Berdasarkan tinjauan secara mendalam melalui 5 (lima) kerangka terori tersebut diatas, maka dikembangkan hipotesis yang akan diuji pada riset ini sebagai berikut:

H1: Semakin besar Skill Development Fund maka akan semakin tinggi Workforce Competence.

H2: Semakin besar Skill Development Fund terhadap maka akan semakin kuat Skill Development Center.

H3: Semakin tinggi Workforce Competence maka akan semakin kuat Skill Development Center.

H4:Semakin tinggi Workforce Competence maka akan semakin kuat Resource Sharing Innovation.

H5: Semakin kuat Resource Sharing Innovation maka akan semakin kuat Skill Development Center.

H6: Semakin kuat Resource Sharing Innovation maka semakin tinggi Human Resources Industries Competitiveness.

H7: Semakin kuat Pengaruh Skill Development Center maka akan semakin tinggi Human Resources Industries Competitiveness.

\section{METODE PENELITIAN}

Penelitian ini menggunakan prosedur Research and Development (R\&D) dengan target terumuskannya model kondisi sosial ekonomi pengangguran yang menyebabkan kemiskinan di wilayah industri. Lokasi penelitian dilakukan di tiga wilayah indsutri terbesar di Provinsi Banten yaitu Kab. Serang, Kota Cilegon dan Kab. Tangerang. Daerah tersebut memiliki jumlah penganggur yang paling banyak diantara daerah lainnya di Banten. Metode pengambilan data menggunakan teknik purposive sampling. Dimana sampel dipilih dari populasi pemagangan. Kuisioner dalam penelitian ini didistribusikan kepada semua karyawan yang mengikuti 3 in 1 yang sudah lulus dan bekerja. Ada 250 kuesioner yang dibagikan kepada semua karyawan, dan 217 karyawan mengisi kuesioner dan dapat dikelola dengan tepat.

Selanjutnya untuk memperkuat penelitian ini, data pendukung berupa wawancara dengan dengan stakeholder dari perusahaan manufaktur, berdasarkan wilayah cakupan penelitian yaitu Kabupaten Serang direpresentasi oleh peserta magang pada PT. Eagle Nice (Perusahaan Penanaman Modal Asing/PMA asal Taiwan). Kabupaten Tangerang direpresentasi dari peserta magang PT. Stanley Indonesia (PMA asal Jepang), PT. Sungidas (PMA asal Korea Selatan), PT. Sanken Argadwija (Penanaman Modal Dalam Negeri/PMDN) dan PT. Tomang Mas (PMDN). Kota Cilegon direpresentasi oleh PT. Dover (PMA asal Singapura) dan PT. Krakatau Steel (BUMN).

Variabel yang diukur dalam penelitian ini adalah Skill Development Center, Workforce Competence, Resources Sharing Innovation dan Human Resources Industries Competitiveness , sedangkan variabel bebasnya adalah Skill Development Fund. Semua variabel diukur dengan indikator yang disajikan kepada semua responden melalui kuesioner (skala Likert 1-10). Setiap Jawabannya semakin dekat ke 1 sama sekali tidak setuju sementara Jawabannya mendekati 10 adalah sangat setuju. Data dan pengujian hipotesis dilakukan melalui metode Structural Equation Modelling (SEM) menggunakan program aplikasi IBM AMOS versi 22. 


\section{HASIL DAN PEMBAHASAN}

Deskripsi responden menjelaskan mengenai jenis kelamin, status perkawinan dan usia. Hasil deskrispsi responden selangkapnya selengkapnya disajikan pada tabel di bawah ini.

Tabel 2. Deskripsi Responden

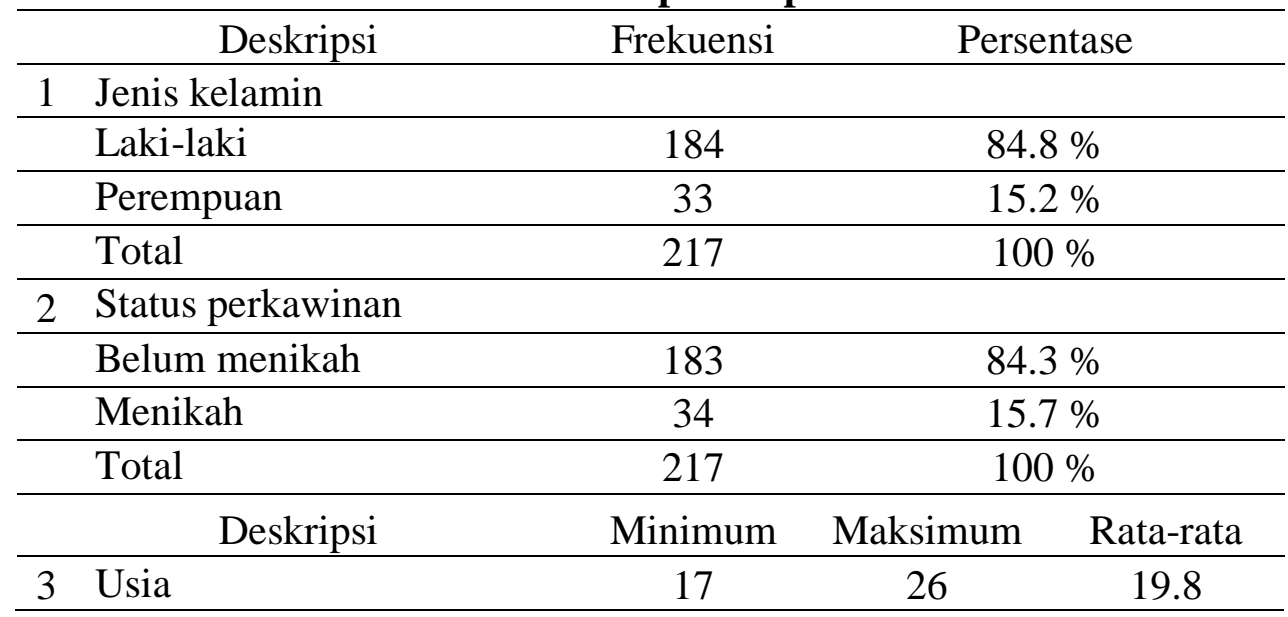

Deskripsi responden dalam penelitian ini dari 217 responden sebagai sampel dan seluruhnya berlatar belakang lulusan Sekolah Menengah Kejuruan.

Pada model CFA ini dilakukan untuk menguji indikator-indikator pada masing-masing variabel laten dan huubungan antar variabel laten. Pengujian indikator dilakukan dengan melihat nilai loading indikator terhadap variabel laten baik untuk variabel eksogen maupun endogen. Jika nilai loading indikator $>0.7$ maka indikator tersebut valid sebagai pengukurnya. Hasil selengkapnya disajikan pada mode CFA di bawah ini.

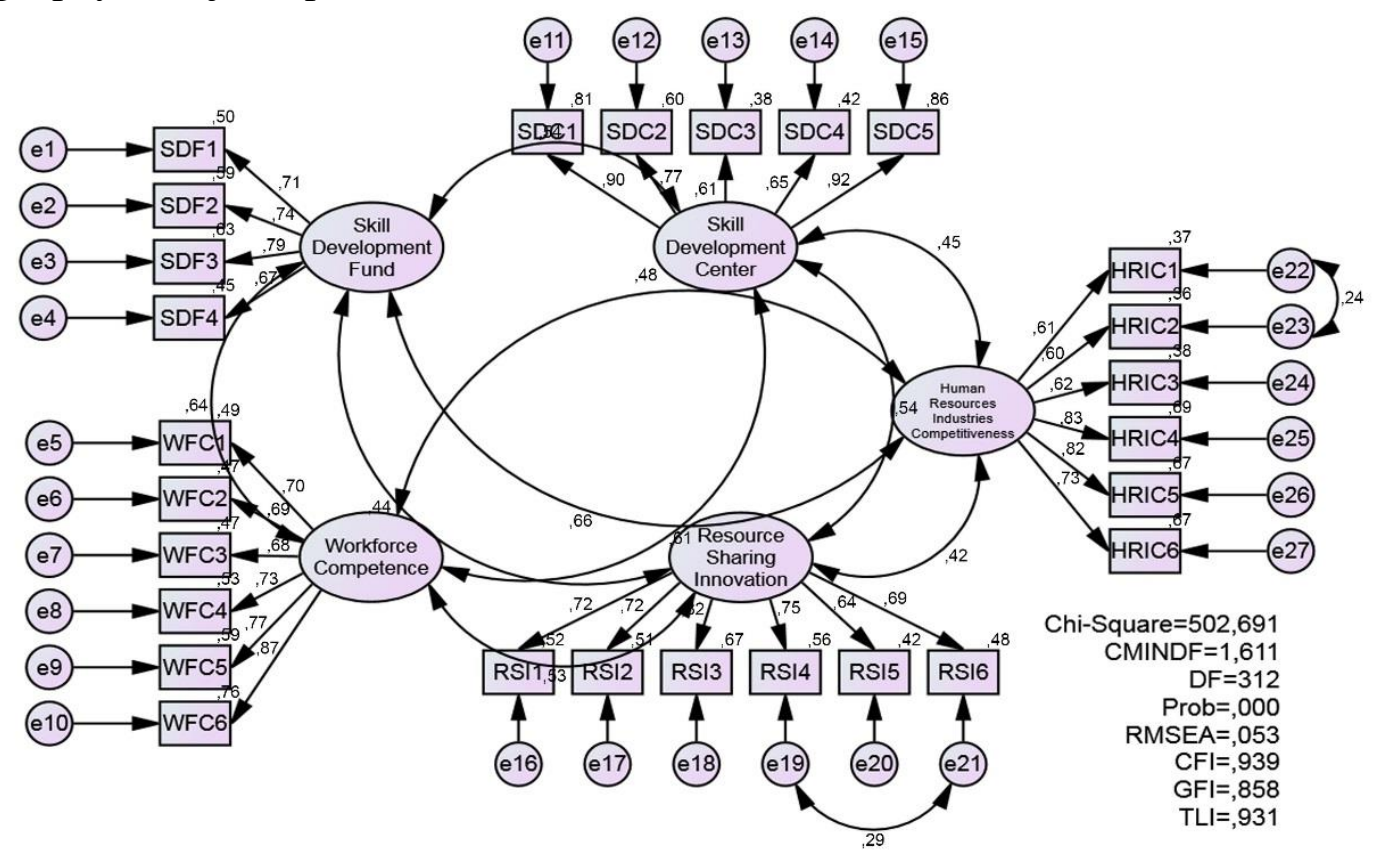

Gambar 1. Model Confirmatory Factor Analysis

Pada model CFA di atas menunjukkan bahwa model menghasilkan nilai RMSEA sebesar 0.053, CFI 0.939, GFI 0.858 dan TLI 0.931 secara umum dapat dikatakan bahwa model sudah layak. Hasil uji CFA menunjukkan bahwa model dapat diterima karena sudah memenuhi criteria yang disyaratkan. Kemudian dari model CFA dikembangkan menjadi model struktural sesuai 
dengan hipotesis dan model yang dikembangkan. Hasil model struktural selengkapnya disajikan sebagai berikut :

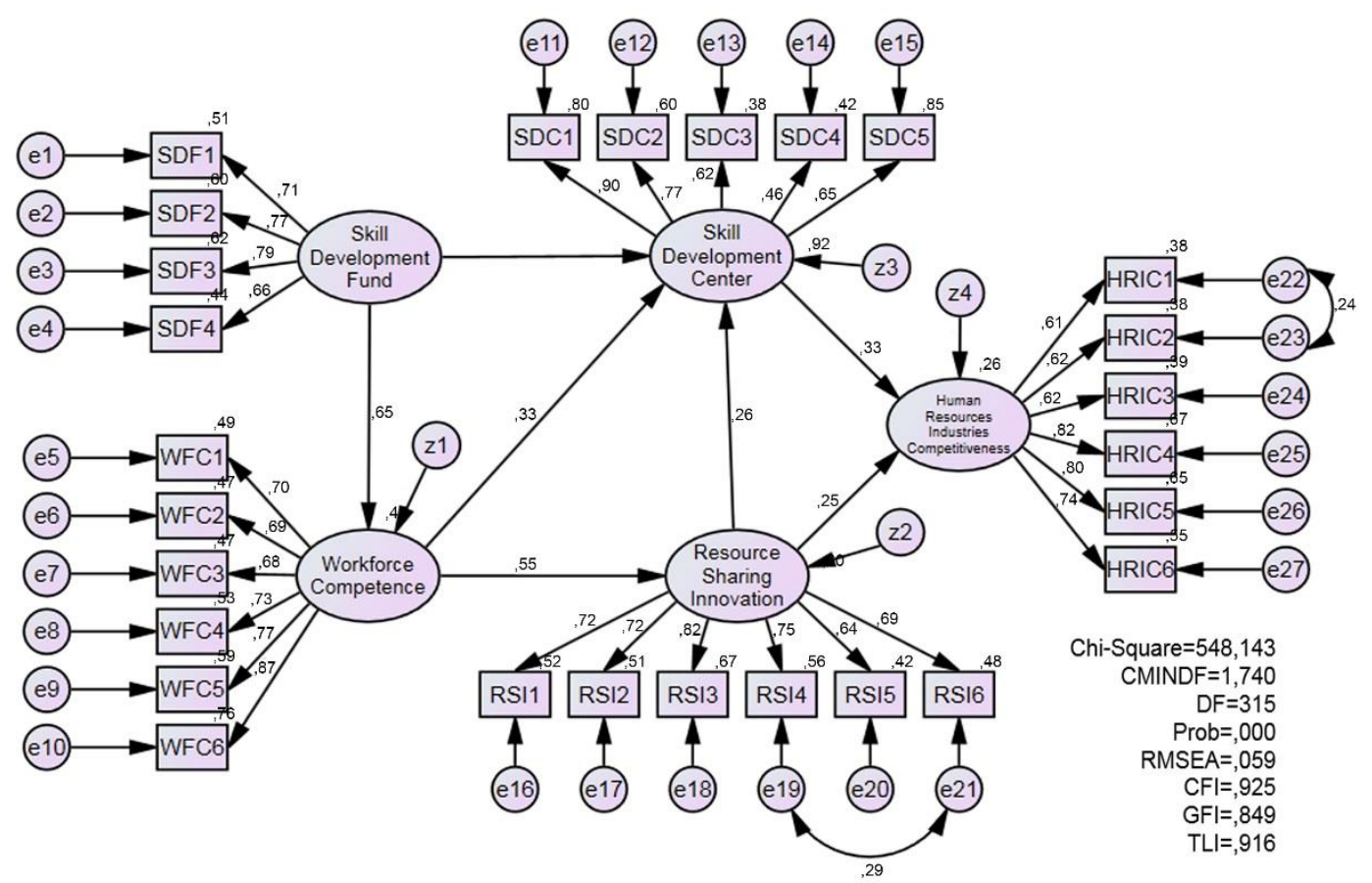

Gambar 2. Model Human Resource Industries Competitiveness

Hasil output model Structural Equation Modeling selengkapnya disajikan pada tabel di bawah ini.

Tabel 3. Regression weight Pengujian Hipotesis Full Model

\begin{tabular}{|c|c|c|c|c|c|c|}
\hline \multicolumn{2}{|c|}{ Jalur Pengaruh } & Estimate & S.E. & C.R. & $\mathbf{P}$ & Keterangan \\
\hline SDF & $\rightarrow \mathrm{WFC}$ & ,615 & ,087 & 7,075 & $* * *$ & Signifikan \\
\hline WFC & $\rightarrow \mathrm{RSI}$ & ,570 & ,089 & 6,413 & $* * *$ & Signifikan \\
\hline SDF & $\rightarrow \mathrm{SDC}$ & ,307 &, 122 & 2,512 &, 012 & Signifikan \\
\hline WFC & $\rightarrow \mathrm{SDC}$ & ,478 &, 145 & 3,296 & $* * *$ & Signifikan \\
\hline RSI & $\rightarrow \mathrm{SDC}$ & ,370 &, 108 & 3,443 & $* * *$ & Signifikan \\
\hline SDC & $\rightarrow$ HRIS & ,230 & ,061 & 3,766 & $* * *$ & Signifikan \\
\hline RSI & $\rightarrow$ HRIS & ,247 & ,087 & 2,839 &, 005 & Signifikan \\
\hline
\end{tabular}

$* * *$ signifikan $<0.001$

Pengujian model empiris dilakukan dengan menguji hipotesis yang dikembangkan dari model. Jika nilai critical ratio $(\mathrm{CR})>1.96$ dan p-value $<0.05$ maka tolak $\mathrm{H} 0$ dan terima $\mathrm{H} 0$ jika nilai critical ratio $<1.96$ dan $\mathrm{p}$-value $>0.05$. Hasil pengujian hipotesis selengkapnya melalui diskusi sebagai berikut :

Pertama, hasil pengujian statistik pada nilai estimasi pengaruh Skill Development Fund terhadap Workforce Competence (Kompetensi Lulusan Sekolah Vokasi) sebesar 0.615, nilai CR 7.075 dan p-value 0.000. Berdasarkan hasil tersebut maka dapat disimpulkan bahwa terbukti Skill Development Fsignifikan berpengaruh positif terhadap rce Competence (Kompetensi Lulusan Sekolah Vokasi) pada tingkat signifikansi 5\%. Hasil pengujian ini memperlihatkan bagaimana peran dana pelatihan yang dipinjamkan kepada para lulusan SMK sebagai pencari kerja untuk mengakses berbagai pelatihan yang diinginkan, namun harus sesuai dengan kebutuhan industri sektor manufaktur. Angka pengangguran di Provinsi Banten yang tertinggi 
secara nasional, dimana kontribusi terbesar dari para lulusan SMK semakin terkuat factor penyebabnya, yaitu belum memadainya kompetensi yang dikuasai dengan tututan industri sektor manufaktur, namun belum terdapat dukungan pendanaan bergulir pelatihan untuk up skilling.

Kedua, hasil pengujian statistik pada nilai estimasi pengaruh Skill Development Fund terhadap Skill Development Center (SDC) sebesar 0.307, nilai CR 2.512 dan p-value 0.012. Berdasarkan hasil tersebut maka dapat disimpulkan bahwa terbukti Skill Development Fund signifikan berpengaruh positif terhadap Skill Development Center pada tingkat signifikansi 5\%. Temuan ini membuktikan bahwa jika Dana Bergulir Pelatihan tersedia, maka peran SDC akan lebih konkrit dalam mengoptimalkan identifikasi kebutuhan sumber daya manusia pada industry sektor manufaktur. Konfirmasi terkait dengan hal ini sebagaimana yang disampaikan oleh Direktur Eksekutif SDC Provinsi Banten.

Ketiga, hasil pengujian statistik pada nilai estimasi pengaruh Workforce Competence terhadap Skill Development Center sebesar 0.478, nilai CR 3.296 dan p-value 0.000. Berdasarkan hasil tersebut maka dapat disimpulkan bahwa terbukti Workforce Competence signifikan berpengaruh positif terhadap Skill Development Center (SDC) pada tingkat signifikansi 5\%. Temuan ini semakin membuktikan bahwa para lulusan SMK yang memiliki kompetensi dan berdaya saing yang belum media, jika langsung masuk ke pasar kerja. Diperlukan tahapan antara melalui program $4 \mathrm{D}$ berbasis demand driven industri sektor manufaktur. Kelembagaan SDC lebih tepat memerankan diri sebagai dirigen dalam orkestrasi berbagai pemangku kepentingan dalam bidang penyiapan daya saing SDM industri sektor manufaktur. Peranan SDC adalah tepat dijadikan wahana untuk melakukan komunikasi, koordinasi, dan sinkronisasi program dan kegiatan peningkatan keahlian tenaga kerja yang melibatkan tiga unsur utama pemangku kepentingan bidang ketenagakerjaan, yaitu pemerintah (pemerintah pusat dan pemerintah daerah), lembaga pendidikan/pelatihan, dan dunia usaha/industry (Bappenas RI, 2018).

Keempat, hasil pengujian statistik pada nilai estimasi pengaruh Workforce Competence terhadap Resource Sharing Innovation sebesar 0.570, nilai CR 6.413 dan p-value 0.000 . Berdasarkan hasil tersebut maka dapat disimpulkan bahwa terbukti Workforce Competence signifikan berpengaruh positif terhadap Resource Sharing Innovation pada tingkat signifikansi 5\%. Pencapaian kompetensi rerata lulusan SMK di Provinsi Banten masih belum menggembirakan yang disebabkan beberapa faktor antara lain: Ketidaksesuaian program keahlian dengan kebutuhan industry sektor maufaktur dan Minimnya sarana dan prasarana di SMK.

Kelima, hasil pengujian statistik pada nilai estimasi pengaruh Resource Sharing Innovation ke Skill Development Center sebesar 0.370, nilai CR 3.443 dan p-value 0.000. Berdasarkan hasil tersebut maka dapat disimpulkan bahwa terbukti Resource Sharing Innovation signifikan berpengaruh positif terhadap Skill Development Center pada tingkat signifikansi 5\%. Temuan ini memberikan gambaran bahwa Resource Sharing Innovation akan memudahkan Skill Development Center melakukan koordinasi dengan pemangku kepentingan terkait dengan ketersediaan workplace dan proyeksi kebutuhan SDM industri. Hal ini ditegaskan oleh Direktur PT. Eagle Nice produsen pakaian olah raga.

Keenam, hasil pengujian statistik pada nilai estimasi pengaruh Skill Development Center (SDC) ke Human Resource Industries Competitiveness sebesar 0.230, nilai CR 3.776dan p-value 0.000. Berdasarkan hasil tersebut maka dapat disimpulkan bahwa terbukti Skill development center signifikan berpengaruh positif terhadap Human Resource Industries Competitiveness pada tingkat signifikansi 5\%. Bukti ini menunjukkan bahwa SDC dapat memerankan diri sebagai jembatan koloboratif dengan SMK dan lembaga pendidikan dan pelatihan lain, kementrian, Dinas Tenaga Kerja dan Transmigrasi Provinsi Banten dan kabupaten/kota, Dinas Pendidikan dan Kebudayaan Provinsi Banten dan kabupaten/ kota maupun dengan industry sektor manufaktur di wilayah Provinsi Banten. 
Ketujuh, hasil pengujian statistik pada nilai estimasi pengaruh Resource Sharing Innovation (RSI) ke Human Resource Industries Competitiveness sebesar 0.247, nilai CR 2.839 dan p-value 0.005. Berdasarkan hasil tersebut maka dapat disimpulkan bahwa terbukti Resource Sharing Innovation signifikan berpengaruh positif terhadap Human Resource Industries Competitiveness pada tingkat signifikansi 5\%. Hasil ini membuktikan bahwa keterbukaan untuk melakukan resource sharing dari industri sektor manufaktur telah dilakukan dalam skala kecil, namun belum terstruktur, sistemik dan massif dilakukan oleh para pebisnis sektor ini. Jika hal ini diungkit menjadi gerakan yang massif maka sesuai estimasi akan meningkatkan daya saing insani industry di Provinsi Banten. Keterbukaan untuk melakukan resource sharing perlu dilakukan secara fleksibel tidak kaku serta selalu memperbaharui metodenya agar para pihak yang melakukannya merasakan manfaat secara bersama untuk pengembangan kelembagaan dan bisnis.

\section{SIMPULAN}

Hasil penelitian ini berhasil membuktikan bahwa untuk mengatasi pengangguran di Provinsi Banten memerlukan resources sharing innovation (inovasi berbagi sumber daya) yang akan menjembatani lulusan sekolah vokasi dan lembaga pelatihan agar dapat memanfaatkan fasilitas training centre di perusahaan. Dengan demikian maka semakin terbuka resources sharing innovation maka akan semakin tinggi daya saing lulusan sekolah vokasi dan lembaga diklat dihadapan para pebisnis industri sektor manufaktur. Disamping itu masalah pengangguran juga dapat diatasi dengan kolaborasi para pemangku kepentingan pada sektor pendidikan dan ketenagakerjaan, hal ini dapat diperankan oleh skill development center, yang menjalankan fungsi kolaboratif.

Implikasinya adalah program yang disusun oleh pemerintah untuk mengatasi pengangguran di Provinsi Banten hendaknya dengan cermat mempertimbagkan sumber daya yang dimiliki oleh industry sektor manufaktur yang berjumlah lebih dari 5.000 unit. Resource Sharing layak dipertimbangkan untuk mengurangi beban pemerintah daerah dalam membelanjakan mesin dan peralatan serta biaya operasional balai latihan kerja yang tidak tepat dan masa pakai relative pendek. Penguatan peran Skill Development Center baik pada tingkat Provinsi maupun kabupaten kota agar kolaborasi para pemangku kepentingan sektor pendidikan, ketenagakerjaan dan industry sektor manufaktur berjalan efektif dan optimal serta fokus untuk mengurangi pengangguran. Dana bergulir pelatihan hendaknya mendapatkan prioritas pendiriannya baik secara kelembagaan maupun alokasi dana yang dialokasikan secara memadai selama tiga tahun anggaran, sehingga pendapatan bagi hasilnya dapat digunakan untuk membiayai program $4 \mathrm{D}$ bagi para pencari kerja.

\section{DAFTAR PUSTAKA}

Alghofari, F., 2010. Analisis Tingkat Pengangguran di Indonesia Tahun 1980-2007. Universitas Diponegoro.

Baeti, N., 2013. Pengaruh Pengangguran, Pertumbuhan Ekonomi, Dan Pengeluaran Pemerintah Terhadap Pembangunan Manusia Kabupaten/Kota Di Provinsi Jawa Tengah Tahun 20072011. Economics Development Analysis Journal, 2(3), pp.85-98.

BPS, 2019. Keadaan Ketenagakerjaan Banten Agustus 2019. Banten.

Budiani, N.W., 2005. Efektivitas Program Penanggulangan Pengangguran Karang Taruna " EKA TARUNA BHAKTI " Desa Sumerta Kelod Kecamatan Denpasar Timur Kota Denpasar. Ekonomi dan Sosial INPUT, 2(1), pp.49-57.

Dutta, N., n.d. Keynesian Theory of In-voluntary Unemployment (With Diagram). economics discussion. 
Hadroj, A., 2016. Unemployment - theoretical overview. In: International Scientific ConferenceERAZ. Belgrade: ERAZ.pp.564-571.

Heriansyah, R.D., Nuraini, I. and Kusuma, H., 2018. ANALISIS PENGARUH JUMLAH INDUSTRI DAN INDEKS PEMBANGUNAN MANUSIA TERHADAP JUMLAH PENDUDUK MISKIN DI KABUPATEN/KOTA PROVINSI BANTEN TAHUN 20122016. Jurnal Ilmu Ekonomi, 2(3), pp.453-463.

Imsar, 2018. Analisis Faktor-Faktor Yang Mempengaruhi Tingkat Pengangguran Terbuka Di Provinsi Lampung (Periode 1989-2016). Human Falah, 5(1), pp.144-164.

Jonung, L., 1989. Knut Wicksell on unemployment. Historical of Political Economy, 21(1), pp.27-42.

Machin, S. and Manning, A., 1999. Chapter 47 The causes and consequences of longterm unemployment in Europe. Handbook of Labor Economics, 3 PART(3), pp.3085-3139.

Mouhammed, A.H., 2011. Veblen's theory of unemployment and public policies. International Research Journal of Finance and Economics, 70(5), pp.217-226.

Mulyadi, D., 2012. Manajemen Perwilayahan Industri. Jakarta: Kementrian Perindustrian.

Pigou, A.., 1933. The Theory of Unemployment. Frank Cass And Company Limited.

Rodriguez, R.A., 2015. Classical versus Keynesian Theory of Unemployment : An approach to the Spanish labor market.

Santoso, M.B., 2014. Kompetensi Lokal Dalam Menanggulangi Kemiskinan Di Daerah Industri. Share : Social Work Journal, 4(2).

Setiyawati, A. and Hamzah, A., 2007. Analisis Pengaruh Pad, Dau, Dak, Dan Belanja Pembangunan Terhadap Pertumbuhan Ekonomi, Kemiskinan, Dan Pengangguran: Pendekatan Analisis Jalur. Jurnal Akuntansi dan Keuangan Indonesia, 4(2), pp.211-228.

Winardi, 2017. Dampak Pembangunan Kawasan Industri Terhadap Output, Penyerapan Tenaga Kerja, Distribusi Pendapatan dan Kemiskinan Rumah Tangga di Provinsi Jawa Barat. Program Studi Ilmu Perencanaan Pembangunan Wilayah dan Perdesaan. Institut Pertanian Bogor.

Yacoub, Y. (Universitas T.P., 2012. Pengaruh Tingkat Pengangguran terhadap Tingkat Kemiskinana Kabupaten/Kota di Provinsi Kalimantan Barat. Jurnal EKSOS, 8(3), pp.176185 . 